\title{
Suppression of Plasma Aldosterone by Chronic ACTH Administration is Offseted by Converting Enzyme Inhibitor
}

\author{
Noboru FuKuda, Masanobu honda, Masashi Watanabe, \\ Masaya MINATO and Michinobu HATANO
}

The 2nd Department of Internal Medicine, Nihon University School of Medicine, Ooyaguchi, Itabashi-ku, Tokyo 173, Japan

\begin{abstract}
In order to elucidate the mechanism of suppression of plasma aldosterone by chronic ACTH administration, especially the role of the renin-angiotensin system and dopamine, we administered ACTH with or without MK422, a converting enzyme inhibitor, to reduce the endogenous angiotensin II in rats, and measured the plasma renin activity, plasma corticoid concentrations and urinary dopamine excretion. The plasma aldosterone concentration (PAC) was decreased after chronic ACTH administration. However, in the ACTH+ MK422 administered group, aldosterone suppression was not observed. It appeared therefore that the aldosterone suppressing mechanism was independent of the weakened renin-angiotensin system following chronic ACTH administration, since PAC was not decreased in the ACTH + MK422 administered group when angiotensin II might be completely eliminated. The urinary excretion of dopamine was significantly increased in the chronic ACTH + MK422 administered group as well as in the chronic ACTH administered group. This suggested that the inhibitory effect of dopamine on aldosterone did not contribute significantly to the suppression of plasma aldosterone.

The present results suggest therefore that the mechanism of suppression of plasma aldosterone following chronic ACTH administration was not dependent on the renin-angiotensin system and dopamine.
\end{abstract}

ACTH is not only a major stimulator of glucocorticoid secretion, but is also a very potent stimulator of aldosterone secretion (Williams et al., 1972). It has been found, however, that after chronic administration of ACTH, plasma aldosterone was decreased despite a high concentration of glucocorticoids (Biglieri et al., 1979, Rauh

\section{Received October 2, 1986}

Reprint requests to: Noboru Fukuda, M. D., The 2nd Department of Internal Medicine, Nihon University School of Medicine, Ooyaguchi, Itabashi-ku, Tokyo, 173, Japan et al., 1980, Nussdorfer et al., 1982). Various reports have indicated that the mechanisms of suppression of plasma aldosterone by chronic ACTH administration might be related to the renin-angiotensin system (Gaillard et al., 1983), aldosterone metabolism (Pratt et al., 1976) and inhibition of aldosterone biosynthesis (Müller, 1978, McDougall et al., 1980, Nussdorfer et al., 1982), etc. However, the precise mechanisms have not yet been clarified, and in particular there have been conflicting reports concerning the relation between the renin-angiotensin 
system and suppression of plasma aldosterone (Gaillard et al,, 1983, Oelkers, 1985).

Dopamine has been recognized as a physiological inhibitor of aldosterone secretion (McKenna et al,, 1979). Recently, it was demonstrated that dopamine inhibits 18-hydroxylase of the adrenal gland directly (Sowers et al., 1982). The possibility exists therefore that the inhibitory action of dopamine might lead to suppression of plasma aldosterone. However, there has been no report on this phenomenon.

In the present study, we examined the plasma aldosterone concentration after chronic ACTH administration with or without a converting enzyme inhibitor in order to assess the possible participation of the renin-angiotensin system in the suppression of plasma aldosterone. At the same time, we measured the urinary excretion of dopamine and prostaglandin $\mathrm{E}_{2}$.

\section{Materials and Methods}

Male Wistar rats $(n=32)$, weighing $276.9 \pm 4.1$ (S. E.) g at 9 weeks of age, were used. They were housed and fed with tap water and normal rat chow sontaining $0.26 \mathrm{~g}$ sodium $/ 100 \mathrm{~g}$ and $0.75 \mathrm{~g}$ potassium $/ 100 \mathrm{~g}$ ad libitum.

The rats were divided into 5 groups. Group 1 , the control group, was given sc injections of $0.3 \mathrm{ml}$ saline as the vehicle. Group 2, the chronic ACTH group, was treated with sc injections of $50 \mu \mathrm{g}$ of ACTH-Zn once daily at $1300 \mathrm{~h}$ for 8 consecutive days. Group 3, the chronic ACTH+MK422 group, was treated with ACTH-Zn in the same manner as group 2 and concomitant sc injections of $1 \mathrm{mg} / \mathrm{kg}$ of MK422 dissolved in $0.3 \mathrm{ml}$ saline were given for 9 consecutive days from the day before the first ACTH injection.

Furthermore, to evaluate the influence of the chronic administration of MK422 alone, groups 4 and 5 were prepared for other experiments. Group 4 was given sc injection of $0.3 \mathrm{ml}$ saline as the vehicle once daily at $1300 \mathrm{~h}$ for 9 consecutive days. Group 5, the chronic MK422 group, was treated with MK422 only in the same manner as group 3 .
All rats were housed in metabolic cages from 2 days before taking blood samples and the urine was collected into shielded bottles containing $0.5 \mathrm{ml}$ of $2 \mathrm{~N} \mathrm{HCl}$ for 48 hours, from the day 7 to the day 9 , before the blood sampling. The blood sampling was carried out at about $1000 \mathrm{~h}$ on 9 day after the beginning of ACTH administration, the blood being collected from the carotid artery into tubes containing EDTA. The blood samples were centrifuged at $4^{\circ} \mathrm{C}$ and the plasma was stored at $-20^{\circ} \mathrm{C}$ until analysis.

Plasma aldosterone and deoxycorticosterone (DOC) were measured by radioimmunoassay as described previously (Honda et al., 1976). Plasma 18-hydroxy-deoxycorticosterone (18-OHDOC) was determined by the method described previously (Den et al., 1978). Plasma corticosterone was measured as described previously (Newsome et al., 1972). Plasma renin activity (PRA) was estimated with an RIA-kit of CEAIRE-SORIN (Ueda et al., 1979). Urinary catecolamines were measured by high performance liquid chromatography (Hansson et al., 1979). Urinary prostaglandin $\mathrm{E}_{2}$ was estimated with an RIA kit from New England Nuclear as well as by the method described previously (Inoue et al., 1984.) Urinary electrolytes were determined by flame photometry. Systolic blood pressure was measured by the tail cuff method (Natsume Corporation, Tokyo).

ACTH-Zn was supplied by N. V. Organon Pharmaceutical Co. Ltd., Holland, and MK422 (Enalapril) was supplied by Merk-Banyu Pharmaceutical Co. Ltd., Tokyo.

Statistical significance was assesed by Student's $t$-test for unpaired data and the results were expressed as mean $\pm \mathrm{SE}$.

\section{Results}

As shown in Fig. 1, plasma renin activity (PRA) in the chronic ACTH group $(19.0 \pm 3.3 \mathrm{ng} / \mathrm{ml} / \mathrm{hr})$ was weaker than that in the control group $(27.1 \pm 3.1 \mathrm{ng} / \mathrm{ml} / \mathrm{hr})$, while the PRA concentration in the chronic $\mathrm{ACTH}+\mathrm{MK} 422$ group was significantly higher $(31.4 \pm 2.0 \mathrm{ng} / \mathrm{ml} / \mathrm{hr}, \quad \mathrm{P}<0.01)$ than that in the chronic ACTH group. The plasma aldosterone concentrations (PAC) were $151.7 \pm 14.2 \mathrm{ng} / \mathrm{dl}$ in the control group, 
$112.8 \pm 7.6 \mathrm{ng} / \mathrm{dl}$ in the chronic ACTH group, and $235.3 \pm 47.2 \mathrm{ng} / \mathrm{dl}$ in the chronic ACTH +MK422 group (Fig. 1). These data revealed that after chronic ACTH administration, PAC was decreased significantly $(\mathrm{P}<0.05)$, while PAC in the chronic ACTH + MK422 group significantly higher $(\mathrm{P}<$ 0.05) than that in the chronic ACTH group. On the other hand, the plasma levels of DOC, 18-OH-DOC and corticosterone were significantly higher in both the chronic
ACTH group and the chronic ACTH+ MK422 group $(\mathrm{P}<0.001)$ than those in the control group (Fig. 2).

Concerning the urinary excretion of dopamine, it was significantly greater in both the chronic ACTH group $(1309 \pm 202$ $\mathrm{ng} /$ day, $\mathrm{P}<0.05$ ) and the chronic $\mathrm{ACTH}+$ MK422 group $(1341 \pm 119 \mathrm{ng} /$ day, $\mathrm{P}<0.01)$ than in the control group $(746 \pm 106 \mathrm{ng} /$ day $)$ (Fig. 3). On the other hand, there was no significant difference in the urinary ex-
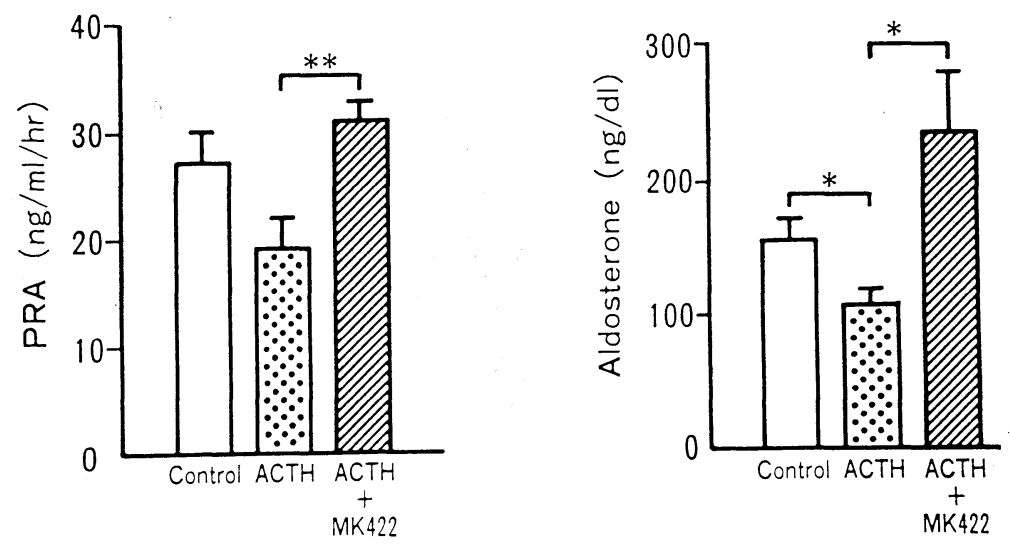

Fig. 1. Comparison of plasma renin activity (PRA) and plasma aldosterone concentration in the control, chronic ACTH and chronic ACTH + MK422 groups.

Vertical bars indicate the mean values $\pm S E$.

$P$ values $(*: P<0.05$, ** $: \mathrm{P}<0.01)$ refer to a comparison between the values for the indicated pairs of groups.
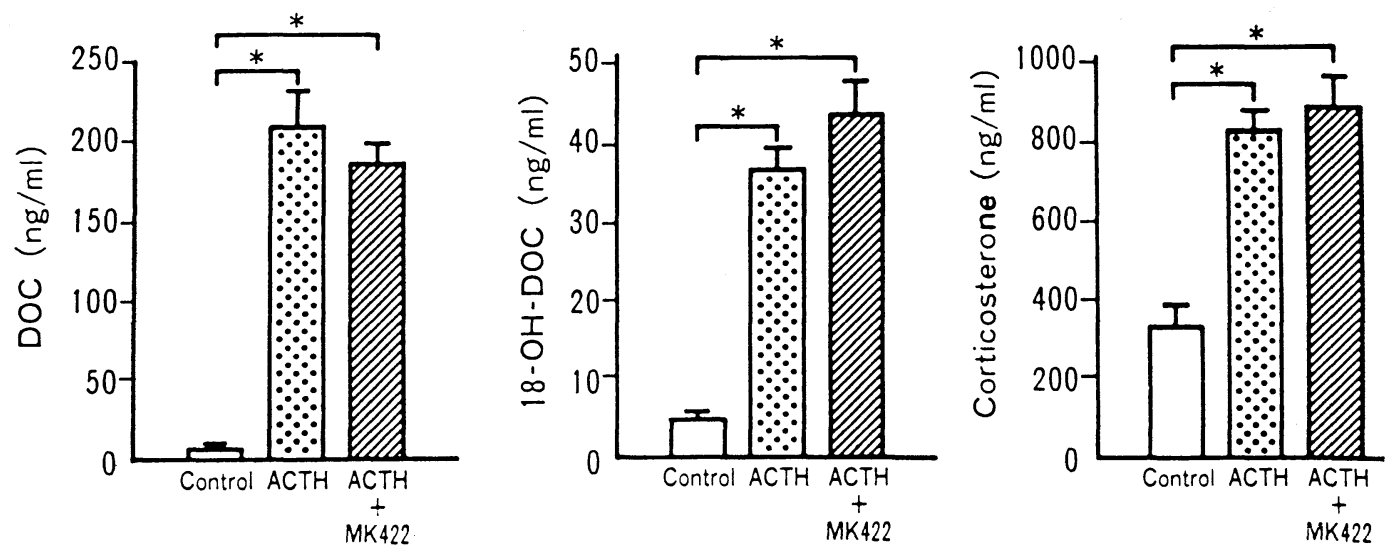

Fig. 2. Comparison of plasma levels of deoxycorticosterone (DOC), 18-hydroxy-deoxycorticosterone (18-OH-DOC) and corticosterone in the control, chronic ACTH and chronic $\mathrm{ACTH}+\mathrm{MK} 422$ groups.

Vertical bars indicate the mean values \pm SE.

$\mathrm{P}$ values $(*: \mathrm{P}<0.01)$ refer to a comparison between the values for the indicated pairs of groups. 
cretion of adrenaline and noradrenaline in the chronic ACTH group and chronic ACTH + MK 422 group as compared to those in the control group, although a similar tendency was observed in the changes in adrenaline and noradrenaline to that seen in the changes in dopamine (Fig. 3). The urine volume was significantly greater $(\mathrm{P}<$ 0.01) in both the chronic ACTH group $(22.4 \pm 3.6 \mathrm{ng} /$ day $)$ and the chronic ACTH + MK 422 group $(22.7 \pm 2.9 \mathrm{ng} /$ day $)$ than in the control group $(8.7 \pm 1.9 \mathrm{ml} / \mathrm{day})$ (Fig. 4). There was no difference in urinary excretion of sodium and potassium among the
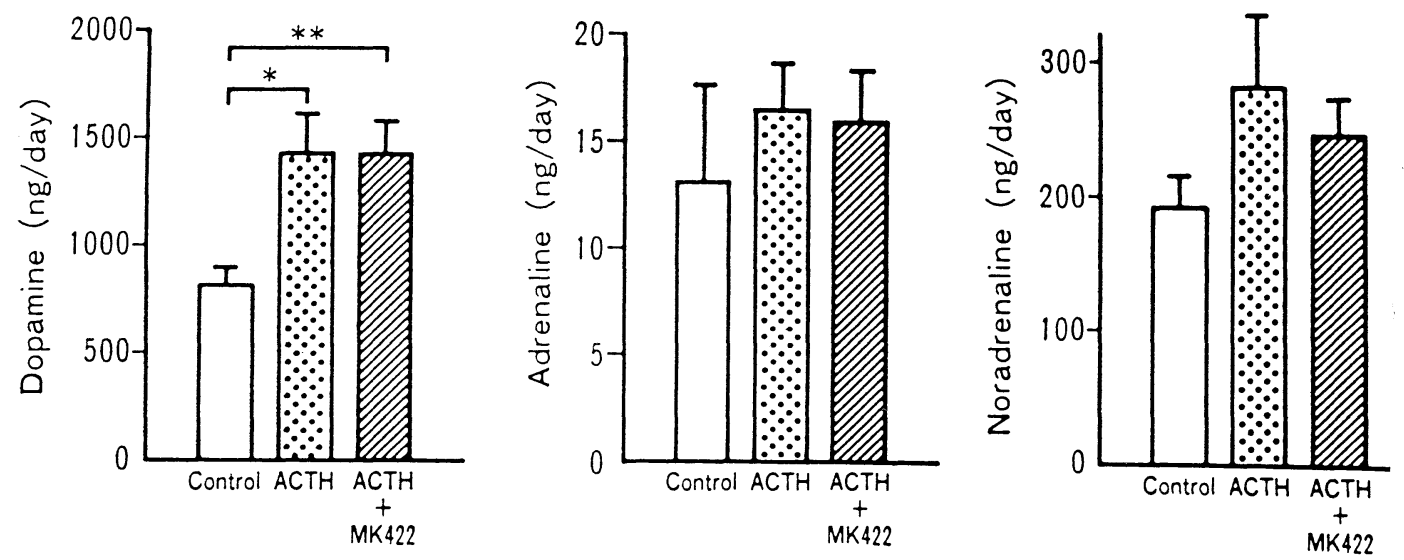

Fig. 3. Comparison of urinary excretions of catecholamines in the control, chronic ACTH and chronic ACTH+MK422 groups.

Vertical bars indicate the mean values \pm SE.

$\mathbf{P}$ values $\left(*: \mathbf{P}<0.05,{ }^{* *}: \mathbf{P}<0.01\right)$ refer to a comparison between the values for the indicated pairs of groups.
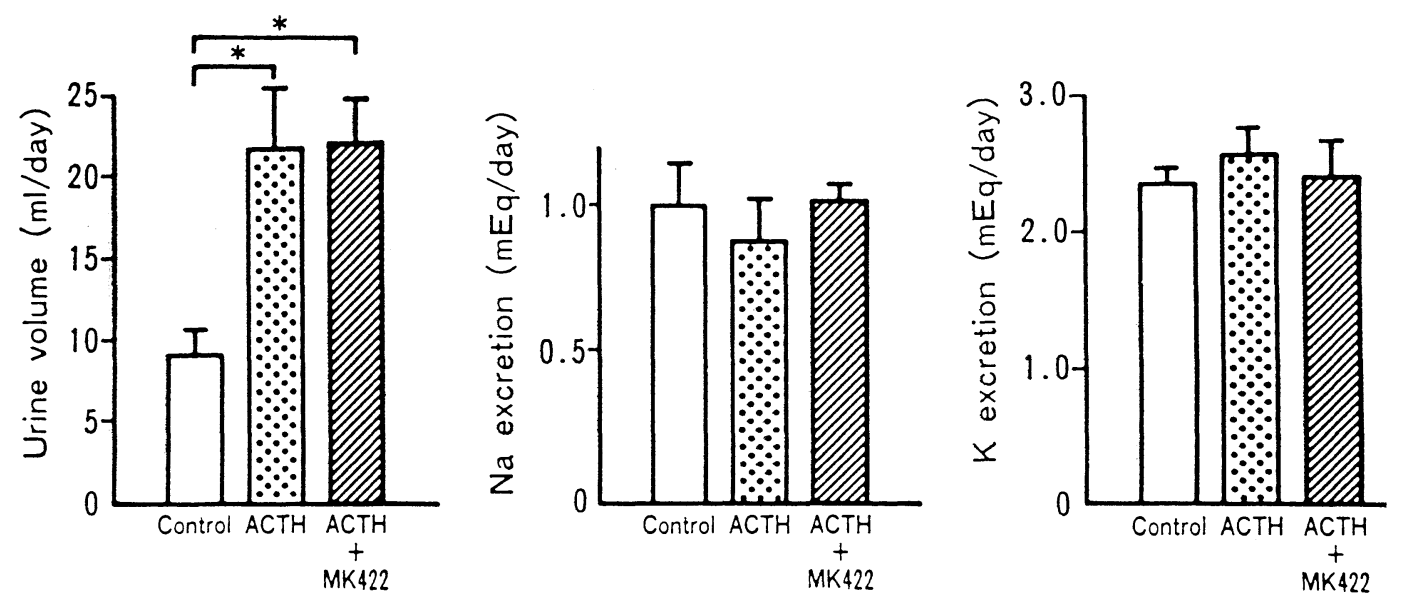

Fig. 4. Comparison of urine volume, and urinary sodium and potassium excretions in the control, chronic ACTH and chronic ACTH + MK422 groups.

Vertical bars indicate the mean values \pm SE.

$\mathbf{P}$ values $(*: \mathbf{P}<0.01)$ refer to a comparison between the values for the indicated pairs of groups. 
3 groups (Fig. 4).

The urinary excretion of $\mathrm{PGE}_{2}$ was measured in pooled urine collected from 6 rats in each group. The values obtained for the chronic ACTH+MK422 group were surprisingly high (Table 1).

The systolic blood pressure in the chronic ACTH group was significantly increased on the 8 th day compared to that in the control group and the chronic ACTH + MK422 group
Table 1. Urinary prostaglandin $\mathrm{E}_{2}$ excretions measured in pooled urine collected from 6 rats from the control, chronic ACTH and chronic ACTH + MK422 groups.

\begin{tabular}{lc}
\hline \hline & $\begin{array}{c}\text { Urinary PGE } \\
\text { excretion }\end{array}$ \\
\cline { 2 - 2 } Control group & $129.8 \mathrm{ng} /$ day \\
Chronic ACTH group & $149.6 \mathrm{ng} /$ day \\
Chronic ACTH+MK422 group & $3640 \mathrm{ng} /$ day \\
\hline
\end{tabular}

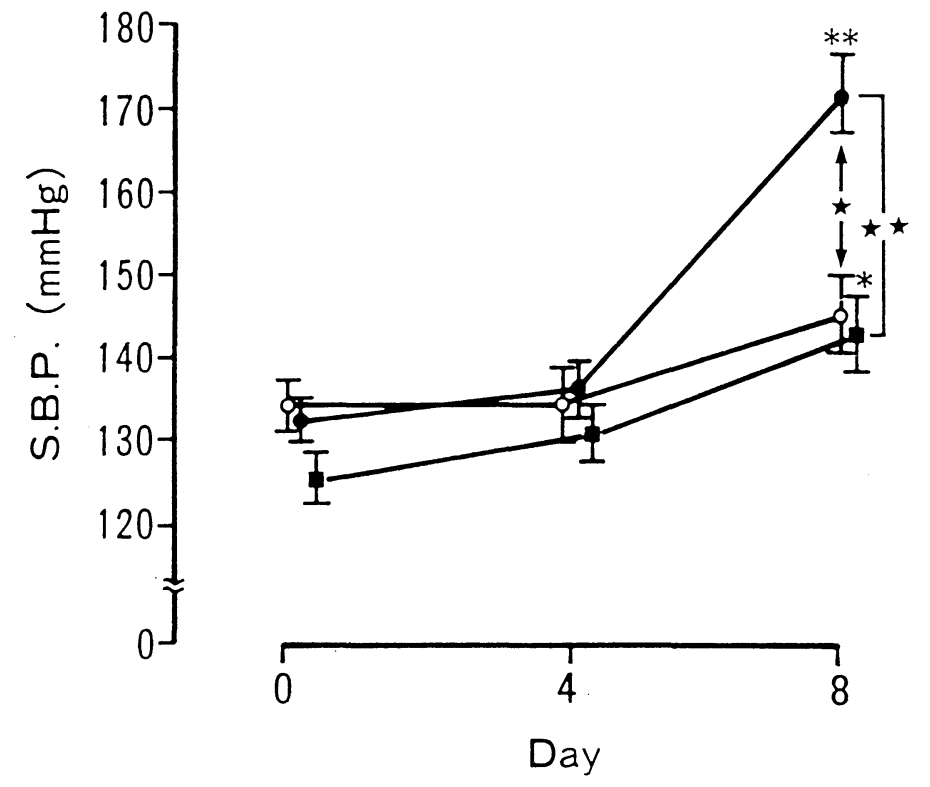

Ffg. 5. Changes in systolic blood pressure (S. B. P.) at $\mathbf{0}$, 4 and 8 days after the beginning of treatment in the control $(\bigcirc-\bigcirc)$, chronic ACTH (-) and chronic ACTH + MK422 ( $\mathbf{\square}-\boldsymbol{\square})$ groups.

Vertical bars indicate the mean values $\pm \mathrm{SE}$.

$\mathbf{P}$ values designated with asteriks $\left(^{*}: \mathrm{P}<0.05\right.$, ** : $\mathrm{P}<$ 0.01) refer to a comparison with the 0 day values. $P$ values designated wtih stars $(\star: \mathrm{P}<0.05, \star \star: \mathrm{P}<0.001)$ refer to a comparison between the values for the indicated pairs of groups.

Table 2. Comparison of plasma renin activity (PRA), plasma concentrations of corticoids, urinary catecholamine excretions, urine volume and urinary electrolyte excretions in the control and chronic MK422 administered groups.

The $\mathrm{P}$ value $(*: \mathrm{P}<0.01)$ refers to a comparison between the values for the 2 groups.

\begin{tabular}{lccc}
\hline \hline & Control group & \multicolumn{2}{c}{ Chronic MK422 } \\
\cline { 2 - 4 } PRA & $9.40 \pm 1.43$ & $23.0 \pm 4.1^{*}$ & $(\mathrm{ng} / \mathrm{ml} / \mathrm{hr})$ \\
Aldosterone & $72.9 \pm 11.3$ & $58.6 \pm 11.3$ & $(\mathrm{ng} / \mathrm{dl})$ \\
DOC & $14.9 \pm 5.4$ & $13.6 \pm 1.1$ & $(\mathrm{ng} / \mathrm{ml})$ \\
18-OH-DOC & $85.2 \pm 18.6$ & $57.8 \pm 8.6$ & $(\mathrm{ng} / \mathrm{ml})$ \\
Corticosterone & $365.7 \pm 66.3$ & $284.4 \pm 22.3$ & $(\mathrm{ng} / \mathrm{ml})$ \\
Urinary dopamine & $745.9 \pm 105.5$ & $701.8 \pm 85.4$ & $(\mathrm{ng} / \mathrm{day})$ \\
Urinary adrenaline & $12.6 \pm 5.1$ & $10.0 \pm 3.1$ & $(\mathrm{ng} /$ day) \\
Urinary noradrenaline & $183.0 \pm 31.9$ & $166.8 \pm 24.6$ & $(\mathrm{ng} /$ day) \\
Urine volume & $10.1 \pm 0.4$ & $11.2 \pm 0.6$ & $(\mathrm{ml} /$ day) \\
Na excretion & $1.71 \pm 0.2$ & $1.68 \pm 0.2$ & $(\mathrm{mEq} /$ day) \\
K excretion & $3.8 \pm 0.3$ & $3.4 \pm 0.3$ & (mEq/day) \\
\hline
\end{tabular}


(Fig. 5). The results indicated that the high blood pressure induced by chronic ACTH administration is abolished by the administration of MK422.

The effects of chronic administration of MK422 only on the PRA, corticoids, urinary catecholamines and electrolytes are summarized in Table 2. The PRA was significantly higher $(\mathrm{P}<0.01)$ than that in the control group. On the other hand, the levels of PAC and other corticoids in the chronic MK422 group were not significantly different from those in the control group. Furthermore, there were no differences in the urinary excretions of catecholamines and electrolytes, and urine volume in these 2 groups (Table 2).

\section{Discussion}

It has been demonstrated by many authors that PAC is increased after acute administration of $\mathrm{ACTH}$, and is decreased after chronic administration of ACTH when the renin-angiotensin system is reduced by elevated mineral corticoids (Biglieri et al., 1979, Rauh et al., 1980, Oelkers, 1985). Conflicting results have been reported for the participation of the reduced reninangiotensin system in the suppression of plasma aldosterone after chronic ACTH administration. Gaillard et al. (1983) found that the suppressed aldosterone response to chronic ACTH administration was more sustained when renin was stimulated by low sodium intake or sodium depletion, suggesting that the suppression of plasma aldosterone was dependent on the reninangiotensin system under normal sodium intake. On the other hand, Rauh et al. (1980) and Oelkers (1985) observed a reduction of aldosterone after chronic ACTH administration under low sodium intake despite a high renin activity, suggesting that the suppression of plasma aldosterone was independent of the renin-angiotensin system.
In order to elucidate the participation of the renin-angiotensin system in the suppression of plasma aldosterone, we administered ACTH chronically to rats concomitantly with MK422, a converting enzyme inhibitor, to reduce the angiotensin II concentration. Regarding the inhibitory effect of MK422 on the renin-angiotensin system, Johnston et al. (1984) investigated the hemodynamic and hormonal effects of a single dose of $10 \mathrm{mg}$ of MK422 in 12 patients with essential hypertension, and demonstrated a similar time course for inhibition of angiotensin converting enzyme, and significant decreses in plasma angiotensin II and aldosterone, with reciprocal increases in blood angiotensin I and plasma renin. In our experiments also, PAC was decreased after chronic ACTH administration. However, the chronic ACTH administration with MK422 significantly increased PAC as compared with the results of the chronic ACTH administration. These data suggest that the reduction of the renin-angiotensin system after chronic ACTH administration is not related to the suppression of plasma aldosterone, since PAC was not decreased after the concomitant administration of converting enzyme inhibitor which reduced the amount of angiotensin II. Another factor should therefore be sought in relation to the suppression of plasma aldosterone.

Recently, several reports have suggested that dopamine plays a role in the regulation of aldosterone secretion (Carey et al., 1979, McKenna et al., 1979). The aldosterone regulatory role of dopamine has been found to be as a tonic inhibitor and to be independent of the renin-angiotensin system (Sower et al., 1980). It has been reported that the site of dopamine inhibition of aldosterone in the adrenal gland was at a late step, especially 18-hydroxylase (McKenna et al., 1979, Sowers et al., 1982). We measured urinary dopamine excretion in an attempt to evaluate the relatianship of dopamine to the suppression of plasma 
aldosterone, since it has been established that the plasma levels of aldosterone and 18-deoxy-corticosterone, at the late step of the adrenal gland, were decreased after chronic ACTH administration (Biglieri et al., 1979, Oelkers, 1985).

At the same time, Baines and Chan, (1980) reported that $30 \%$ of the urinary dopamine is derived from circulating free L-dopa based on a micropuncture study of nephrotubules. It is considered therefore that the urinary dopamine can be used as an index in evaluating the relationship between dopamine and aldosterone. On the other hand, dopamine was found to be increased after sodium loading and to act to reduce blood pressure by a vasodilatory action, enhancing effects on the glomerular filtration rate and natriuresis by inhibiting sodium reabsorption (Lee, 1982).

In the present series of experiments, the significant increases in urinary dopamine excretion in the chronic ACTH group and the chronic $\mathrm{ACTH}+\mathrm{MK} 422$ group appeared to be attributable to sodium retention and volume expansion due to the significantly increased mineral corticoids, such as DOC. Furthermore, an increase in urine volume without any increase in sodium excretion was recognized in the 2 groups. It is possible that the increased urine volume was due to the action of dopamine which was increased in response to the increase in mineralcorticoids.

Regarding the participation of increased dopamine in suppressing plasma aldosterone in the present series of experiments, the increase in dopamine appeared to be independent of the suppression of plasma aldosterone by chronic ACTH administration, since in the chronic ACTH+MK422 group PAC was not decreased in spite of an increase in dopamine to a level as high as that in the chronic ACTH group.

It has been reported that during prolonged ACTH treatment, zona glomerulosa cells may be converted to functional zona fas- ciculata type cells (Müller, 1978, McDougall et al., 1980, Nussdorfer et al., 1982). Recently, Crivello et al., (1982), using bovine adrenal zona glomerulosa cell cultures, found that prolonged treatment with ACTH and angiotensin II decreased the relative aldosterone synthesis, suggesting that the conditions were not sufficient to protest against the loss of activity of aldosterone-synthesizing enzymes due to increased steroidgenesis, including steroid-cytochrome P450 interactions.

Taken together, these results on inhibition of the aldosterone biosynthesis of glomerulosa cells by chronic ACTH administration suggest that ACTH itself acts to convert glomerulosa cells to fasciculata cell types, with functional zonation, and the increased glucocorticoids inhibit cytochrome P450 enzymes to reduce aldosterone biosynthesis.

In the present series of experiments, one possible cause of the obstruction of the aldosterone inhibition by chronic ACTH administration in the chronic ACTH+MK422 group was considered to be that, under the conditions of ACTH treatment, the converting enzyme inhibitor may act to maintain aldosterone synthesis against the ACTH inhibitory effects, as in the case of methylapone which was a most effective agent for maintaining the relative aldosterone synthesis constant at the initial levels under conditions of ACTH and angiotensin II treatment (Crivello et al., 1982), since a single treatment with MK422 did not influence the plasma aldosterone.

On the other hand, in relation to the effects of prostaglandin (PG) on aldosterone biosynthesis, it has been reported that PAC was increased after the administration of PGA in humans (Fichman et al., 1972), while $\mathrm{PGE}_{1}$ and $\mathrm{PGE}_{2}$ stimulated aldosterone biosynthesis through ACTH receptor, but $\mathrm{PGA}, \mathrm{PGF}_{1} \alpha$ and $\mathrm{PGF}_{2} \alpha$ did not exert any aldosterone stimulating effect (Kaplan, 1973). In the present series of experiments, the urinary excretion of $\mathrm{PGE}_{2}$ was markedly 
increased in the chronic $\mathrm{ACTH}+\mathrm{MK} 422$ group compared to the other group. It is possible therefore that the increased $\mathrm{PGE}_{2}$ served to protect the aldosterone inhibition due to chronic ACTH administration.

As an another possible cause of the obstruction of aldosterone inhibition, the effects of changes in serum levels and urinary excretions of electrolytes, especially potassium, can be considered. However, in the present experiments, there was no appreciable difference between urinary sodium and potassium excretions in the chronic $\mathrm{ACTH}$ and ACTH + MK422 groups, indicating that the change in electrolytes was not attributable to the obstruction of aldosterone inhibition observed in the chronic ACTH+ MK422 group.

From the present results alone, the chronic protective mechanism of aldosterone inhibition following chronic ACTH administration cannot be satisfactory clarified. Further studies are needed.

\section{References}

Baines, A. D. and W. Chan (1980). Production of urine-free dopamine from dopa; A micropuncture study. Life Sci. 26, 253-259.

Biglieri, E. G., B. Chang, J. Hirai, N. Brust, C. R. Rost and M. Schambelan (1979). Adrenocorticotropin inhibition of mineralocorticoid hormone production. Clin. Sci. 57, 307s$311 \mathrm{~s}$.

Carey, R. M., M. O. Thorner and E. M. Ortt (1979). Effects of metoclopramide and bromocriptine on the renin-angiotensin-aldosterone system in man: Dopaminergic control of aldosterone. J. Clin. Invest. 63, 727-735.

Crivello, J. F., R. J. Hornsby and G. N. Gill (1982). Metyrapone and antioxydants are required to maintain aldosterone synthesis by cultured bovine adrenocortical zona glomerulosa cells. Endocrinology 111, 469-479.

Den, K., M. Honda, A. Kanbegawa, M. Tomita, B. Tochigi, T. Yoshida and S. Takagi (1978). A radioimmunoassay of plasma 18-hydroxy11-deoxycorticosterone. Endocrinol. Japon. 25, 171-175.
Fichman, M. P., G. Littenberg, G. Brooker and R. Horton (1972). Effect of prostaglandin $A_{1}$ on renal and adrenal function in man. Circulation Res. 31, II-19-II-35.

Gaillard, R. C., A. M. Riondel, C. A. FavrodCoune, M. B. Vallotton and A. F. Müller (1983). Aldosterone escape to chronic ACTH administration in man. Acta Endocrinol. 103, 116-124.

Hanson, C., G. Agrup, H. Rorsman, A. M. Rosengren and E. Rosengren (1979). Analysis of cysteinyldopas, dopa, dopamine, noradrenaline and adrenaline in serum and urine using high-performance liquid chromatography and electrochemical detection. J. Chromatography 162, 7-22.

Honda, M., W. Nowaczynski, F. H. Messerli, O. Kuchel and J. Genest (1976). Plasma deoxycorticosterone and aldosterone in essential hypertension. J. Steroid Biochem. 7, 565-569.

Inoue, T., M. Honda and M. Hatano (1984). Radioimmunoassay method for urinary 6-ketoprostaglandin $\mathrm{F}_{1} \alpha$ and its clinical application. J. Nihon Univ. Med. Ass. 43, 283-294.

Johnston, C. I., B. J. Jackson, I. Larmour, R. Cubella and D. Casley (1984). Plasma enalapril levels and hormonal effects after short- and long-term administration in essential hypertension. Br. J. Cr. Pharmacol. 18, 233S-239S.

Kaplan, N. M. (1973). Endocrinology, edited by R. O. Scow, Excerpta Medica, Amsterdam. 795.

Lee, M. R. (1982). Dopamine and the kidney. Clin. Sci. 62, 439-448.

McDougall, J. G., A. Butkus, J. P. Coghlan, D. A. Denton, J. Muller, C. J. Oddie, P. M. Robinson and B. A. Scogging (1980). Biosynthetic and morphological evidence for inhibition of aldosterone production following administration of ACTH to sheep. Acta Endocrinol. 94, 559-570.

McKenna, T. J., D. P. Island, W. E. Nicholson and G. W. Liddle (1979). Dopamine inhibits angiotensin-stimulated aldosterone biosynthesis in bovine adrenal cells. J. Clin. Invest. 64, 287-291.

Müller, J. (1978). Suppression of aldosterone biosynthesis by treatment of rats with adrenocorticotropin: Comparison with glucocorticoid effects. Endocrinology 103, 2061-2068.

Newsome, H. H., A. S. Clements and E. H. Borum (1972). The simultaneous assay of 
cortisol, corticosterone, 11-deoxycortisol, and cortisone in human plasma. J. Clin. Endocrinol. Metab. 34, 473-482.

Nussdorfer, G. G., G. Neri, A. S. Belloni, G. Mazzocchi, P. Rebuffat and C. Robba (1982). Effects of ACTH on the zona glomerulosa of sodium-loaded timolol maleate-treated rats: Stereology and plasma hormone concentrations. Acta Endocrinol. 99, 256-262.

Oelkers, W. (1985). Prolonged ACTH infusion suppresses aldosterone secretion in spite of high renin activity. Acta Endocrinol. 108, 9197.

Rauh, W., K. Gottesdiener, D. Chow, E. Forster. P. Saenger, L. S. Levine and M. I. New (1980). Aldosterone response to prolonged ACTH infusion in juvenile hypertension. Pediatr. Res. 14, 1035-1039.
Sowers, J. R., M. L. Tuck, T. M. Golub and E. G. Sollars (1980). Dopaminergic modulation of aldosterone secretion is independent of alteration in renin secretion. Endocrinology 107, 937-941.

Sowers, J. R., F. W. J. Beck and G. Berg (1982). Altered dopaminergic modulation of 18hydroxycorticosterone secretion in idiopatic edema: Therapeutic effects of bromocriptine. J. Clin. Endocrinol. Metab. 55, 749-756.

Ueda, Y., M. Honda and M. Hatano (1979). Responses of adrenal steroids to angiotensin II in essential hypertension. J. Steroid Biochem. 11, 1527-1534.

Williams, G. H. and R. H. Dluhy (1972). Aldosterone biosynthesis: Interrelationship of regulatory factors. Am. J. Med. 53, 595-605. 